\title{
Effects of response effort on self-control in rats
}

\author{
JOHN J. CHELONIS, A. W. LOGUE, REBECCA SHEEHY, and JIANBIN MAO \\ State University of New York, Stony Brook, New York
}

\begin{abstract}
Five rats served as subjects in an experiment that examined the effect of increasing response effort on self-control (choice of a larger, more delayed reinforcer over a smaller, less delayed reinforcer). The rats made significantly more self-control choices as the force required to respond on each lever increased from 0.1 to $0.8 \mathrm{~N}$. As the force required to press the levers increased to $1 \mathrm{~N}$ and then began to decrease, some of the rats stopped responding. For those rats that continued to respond, self-control tended to decrease. The results suggest that increasing the required response force can increase selfcontrol choices, as long as the required response force is low enough that some responding occurs.
\end{abstract}

Many methods have been found to enhance self-control, defined as the choice of a larger, more delayed reinforcer over a smaller, less delayed reinforcer (Ainslie, 1974; Grosch \& Neuringer, 1981; Logue, 1988), in both nonhuman and human subjects (see Logue, 1995, for a review). For example, self-control can be increased by using precommitment procedures; subjects can make a precommitment response that prevents them from later choosing the smaller, less delayed reinforcer over the larger, more delayed reinforcer (Ainslie, 1974; Rachlin \& Green, 1972). As another example, self-control can be increased by exposing the subject to delayed reinforcers prior to self-control testing (Eisenberger \& Adornetto, 1986; Eisenberger, Masterson, \& Lowman, 1982; Logue \& Mazur, 1981; Logue, Rodriguez, Peña-Correal, \& Mauro, 1984; Mazur \& Logue, 1978). Further, when subjects can change their choices during the delay to the larger reinforcer, prior exposure to delayed reinforcers can increase a subject's tendency to maintain its self-control choice, as well as its tendency to make an initial selfcontrol choice (Logue \& Peña-Correal, 1984).

Generalized exposure to high response effort has also been found to increase subjects' subsequent choices of a larger reinforcer that requires more effort to obtain over a smaller reinforcer that requires less effort to obtain (Eisenberger \& Adornetto, 1986; Eisenberger, Mitchell, \& Masterson, 1985; Eisenberger, Weier, Masterson, \& Theis, 1989). However, the effects of response effort on subjects' choices of larger, more delayed reinforcers rather than smaller, less delayed reinforcers are not entirely understood. Eisenberger et al.'s experiments have typically manipulated response effort by increasing the ratio re-

\footnotetext{
We thank R. Reeder, G. Higgins, and R. Chorley for their maintenance of the computers and apparatus. A.W.L. is now in the Department of Psychology at Baruch College, City University of New York; R.S. is now in the Department of Psychology, State University of New York at Buffalo. Correspondence and requests for reprints should be addressed to J. J. Chelonis, The Arkansas Children's Hospital, Department of Pediatrics/CARE, 800 Marshall St., Little Rock, AR 72202 (e-mail: chelonis@care.ach.uams.edu).
}

quirement on some task to obtain the reinforcer. Using such a procedure not only increases the effort required to obtain the reinforcer but also exposes the subject to delayed reinforcers, because of the time between initiation of the ratio schedule and receipt of the reinforcer. Therefore, it is possible that exposure to the delayed reinforcers might have confounded any independent contribution that increasing response effort might have had on increasing self-control. In addition, the research conducted by Eisenberger and his colleagues has only examined the effects of past experience with response effort on subsequent self-control testing.

In sum, there has been no attempt to examine the direct and independent effect on self-control of increasing response effort. This is unfortunate, because there are at least two possible reasons why increasing the effort required to obtain both the larger reinforcer and the smaller reinforcer might prove an effective means for increasing self-control. First, many animals increase meal size and decrease meal frequency when the amount of effort required to initiate a meal is increased by increasing the ratio requirement to initiate a meal (Collier, 1982; Collier \& Rovee-Collier, 1980). Similarly, the size of prey that animals typically select also increases as the distance between the prey and the predator is increased (see Stephens \& Krebs, 1986, for a review). Therefore, increasing response effort should increase subjects' preferences for a larger meal and, thus, possibly self-control.

Second, models of choice behavior, such as the generalized matching law (Baum, 1974; Logue et al., 1984), incentive theory (Fantino \& Davison, 1983; Killeen, 1982), and the hyperbolic decay model (Mazur, 1984), assume that preference for a given alternative is a function of the amount of reinforcer received for both alternatives. One way of modifying these models so as to incorporate response effort is to define reinforcer amount as the net amount of energy received from a reinforcer (amount of received reinforcer minus the cost of obtaining the reinforcer). Then, all of the models predict that choices of the larger, more delayed reinforcer should increase as the cost of obtaining both reinforcers increases. For exam- 
ple, according to the generalized matching law, if a person were offered a choice between $\$ 6$ and $\$ 2$, the larger amount would be worth three times as much as the smaller amount. However, if that person was offered the same choice at a cost of $\$ 1$, the final outcome for each alternative is $\$ 5$ and $\$ 1$, making the larger amount now worth five times as much as the smaller amount, and preference for the larger alternative should increase. Similarly, if the cost of responding for rats is increased by increasing the amount of energy necessary to obtain a reinforcer, the rats should demonstrate more self-control, because of the increase in value of the larger reinforcer, as compared with the smaller reinforcer.

The present experiment directly examined the effect of response effort on self-control. In order not to confound response effort and delay to reinforcement, rather than altering response effort using a response ratio requirement, response effort was changed for both choice alternatives by altering the force required to operate the response manipulanda. In addition, in the present experiment, a procedure was used in which a subject could change its choice during the larger reinforcer delay (see Logue \& Peña-Correal, 1984). This procedure was used because it provides a good model for self-control outside of the laboratory, where subjects often not only initially have to make a self-control choice but have to refrain from making an impulsive choice at a later time (see Logue, 1995; Logue \& Peña-Correal, 1984). Additionally, this procedure allowed the examination of the hypothesis that, not only would response effort increase a subject's initial self-control choices, but it would also increase a subject's tendency to maintain a self-control choice. Finally, in order to determine whether degree of self-control depends on past, as well as present, levels of response effort, both ascending and descending amounts of response effort were examined in this experiment.

\section{METHOD}

\section{Subjects}

The subjects were 5 experimentally naive male Sprague-Dawley rats. They were maintained at $80 \%$ of their free-feeding weights, using supplemental feedings $30 \mathrm{~min}$ after the completion of each session. Each subject began the experiment at 6 months of age and remained in the experiment for the rest of its life.

\section{Apparatus}

The experiment was conducted in a standard, sound-attenuated rat experimental chamber, $20 \mathrm{~cm}$ high, $23 \mathrm{~cm}$ wide, and $21 \mathrm{~cm}$ deep. The side and top panels of the chamber were Plexiglas, the front and back panels were aluminum, and the floor consisted of metal rods spaced $1 \mathrm{~cm}$ apart for the entire length of the chamber. There were two response levers mounted on the front wall, $6.5 \mathrm{~cm}$ above the floor and $5 \mathrm{~cm}$ apart. Each lever initially required a force of a minimum of $0.1 \mathrm{~N}$ to operate. Each lever's minimum force requirement could be increased in $0.1-\mathrm{N}$ increments by attaching weights to the end of the lever that protruded outside of the chamber. Inside the chamber, above each lever, were two $2-W$ lights. The lights above the left lever could be illuminated green and the lights above the right lever could be illuminated red. An opening in the front wall, $5 \mathrm{~cm}$ in diameter, located between the two levers and $2 \mathrm{~cm}$ above the floor, allowed access to a dipper that contained sweetened condensed milk and could be illuminated with a $2-W$ white light. The dipper held a total of $1.4 \mathrm{ml}$ of liquid, which was more than could be consumed during the reinforcer access period (Tobin, Chelonis, \& Logue, 1993). Above the chamber's ceiling were one 7.5-W white light, one 7.5-W green light, and one 7.5-W red light, which could illuminate the chamber. An exhaust fan provided background noise and ventilation throughout the experiment.

Although rats do not have color vision (Neitz \& Jacobs, 1986), red and green lights were used in the present procedure for two reasons. First, this kept the procedure as similar as possible to previous self-control experiments with pigeons, humans, and monkeys (see, e.g., Tobin \& Logue, 1994; Tobin, Logue, Chelonis, Ackerman, \& May, 1996). Second, using a procedure similar to that used here, it has been demonstrated that rats have the ability to discriminate between the response alternatives (Tobin et al., 1993).

An IBM-XT computer, located in another room, controlled the presentation of stimuli and recorded responses, using a CONMAN program.

\section{Procedure}

All of the rats were first trained to press the levers, using an autoshaping procedure. This consisted of a short-delay conditioning procedure, during which the lights above one of the levers (randomly determined) were illuminated $4 \mathrm{sec}$ prior to reinforcer delivery and remained on during the 6-sec period of food access. There was a $36-\mathrm{sec}$ intertrial interval (ITI) between food access and the next illumination of lever lights. If the rat pressed the lever while the lights were illuminated, food access began immediately. After the rats were responding on both levers, they were tested for self-control, using a discrete-trials procedure in which they could change their choice during the delay to the larger reinforcer (see Logue \& Peña-Correal, 1984).

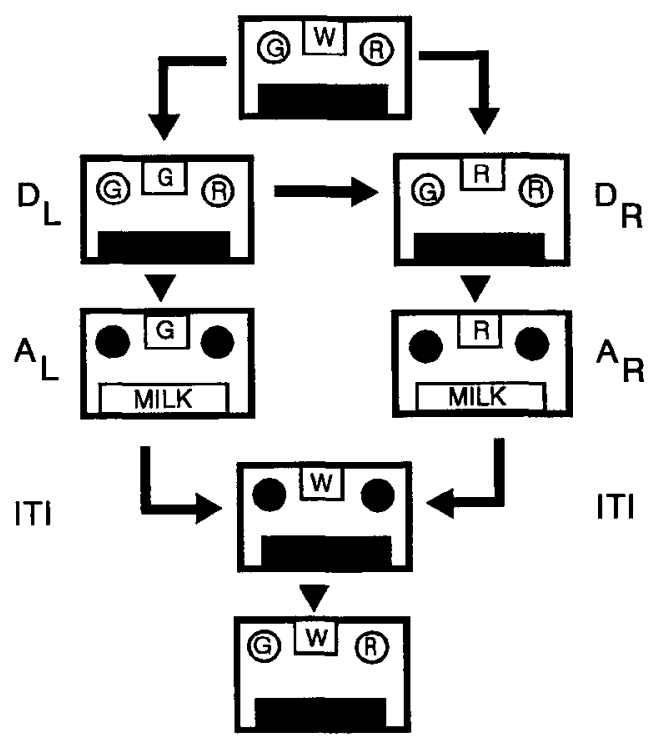

Figure 1. Diagram of the procedure for one trial. Each large rectangle represents a stage of a trial. The small rectangles at the top of the larger ones represent illumination of colored houselights (white, green, or red). The circles represent illumination of the lights above the levers. The small rectangles at the bottom of the large rectangles indicate when the subject had access to the reinforcer. Finally $D_{L}, D_{R}, A_{L}$, and $A_{R}$ represent the left and right reinforcer delays and reinforcer access times (i.e., amounts), respectively. 
Figure 1 diagrams the procedure for one reinforcement cycle. At the beginning of a session, the experimental chamber was illuminated by the white houselight, the lights above the left lever were illuminated green, and the lights above the right lever were illuminated red. An effective left leverpress initiated a delay period (time between a choice and reinforcer access), turning off the white houselight and turning on the green overhead light. Following the completion of the delay period, the lights over both levers were turned off, and the rats were given access to milk. After completion of milk access, the green overhead light was turned off and the white houselight was illuminated for the duration of the ITI. The events following a right leverpress were similar, except that the red overhead light was used instead of the green overhead light.

The length of the ITI was adjusted so that a total of 1 min elapsed from the beginning of one trial to the beginning of the next trial, thus controlling for reinforcer frequency. If the period between the beginning of one trial and the completion of reinforcer access was greater than $1 \mathrm{~min}$, the next trial began as soon as reinforcer access was completed (i.e., there was no ITI). With this procedure, prebut not postreinforcer delays were fixed. However, previous research has found that subjects are relatively insensitive to variations in postreinforcer delays (see, e.g., Logue, Smith, \& Rachlin, 1985).

During the delay to the larger reinforcer, a response on the same lever as the one that had initiated that delay period had no effect. However, a response on the opposite lever prior to the termination of the delay resulted in delivery of the smaller reinforcer after a 0.1 sec delay, along with the appropriate colored overhead light. Responses during the delay to the smaller reinforcer, during reinforcer access periods, and during ITIs had no effect.

Each session consisted of 28 free-choice trials and 6 forcedchoice trials. The rats remained in the experimental chamber for a minimum of $34 \mathrm{~min}$. They were removed from the chamber following completion of the trials or after $45 \mathrm{~min}$, whichever came first. The forced-choice trials ensured that the rats were exposed to the contingencies for each alternative. These trials were similar to the free-choice trials, except that only the lights above one of the levers were illuminated and only responses on that lever were effective in initiating a delay period. During these forced-choice trials, responses during reinforcer delays had no effect. There were three left forcedchoice trials, and three right forced-choice trials, distributed evenly throughout the session.

Table 1 shows the number of sessions that each rat was exposed to each condition. The conditions differed in terms of the minimum amount of force necessary to operate the levers and in terms of the lever on which an effective response would result in a larger, more delayed reinforcer (6-sec delay and 6-sec access to milk), versus a smaller, less delayed reinforcer $(0.1-\mathrm{sec}$ delay and $2-\mathrm{sec}$ access to milk). The contingencies for responses on the two levers remained constant throughout each condition in order to provide both visual and position cues to aid the rat in discriminating the contingencies for responding on each lever. The conditions were ordered such that the required response force increased and then decreased, with the members of each subsequent pair of conditions being identical, except for the levers to which the larger, more delayed and the smaller, less delayed reinforcers were assigned. Rats 1, 2, and 3 began the experiment with the larger, more delayed reinforcer assigned to the left lever, and Rats 4 and 5 with the larger, more delayed reinforcer assigned to the right lever. For subsequent conditions, either response effort or the side to which the larger, more delayed reinforcer was assigned was changed for each group of rats.

Conditions were changed for an individual subject, or group of subjects, when certain stability criteria were satisfied. These criteria specified that, first, the subject had to be exposed to a given condition for a minimum of 10 sessions. Also, for a given rat, in the last 5 sessions of a condition, none of the values for the proportion of
Table 1

Number of Sessions of Exposure to Each Condition for Each Subject

\begin{tabular}{|c|c|c|c|c|c|c|}
\hline \multirow[b]{2}{*}{ Condition } & \multirow{2}{*}{$\begin{array}{c}\text { Force Required to } \\
\text { Press Lever (in Newtons) }\end{array}$} & \multicolumn{5}{|c|}{ Subject Number } \\
\hline & & 1 & 2 & 3 & 4 & 5 \\
\hline 1 & 0.1 & $24^{\mathrm{a}}$ & $24^{a}$ & $24^{a}$ & $20^{\mathrm{b}}$ & $20^{\mathrm{b}}$ \\
\hline 2 & 0.1 & $14^{\mathrm{a}}$ & $14^{\mathrm{a}}$ & $14^{\mathrm{a}}$ & $46^{\mathrm{b}}$ & $46^{\mathrm{b}}$ \\
\hline 3 & 0.2 & $19^{a}$ & $19^{\mathrm{a}}$ & $19^{\mathrm{a}}$ & $19^{\mathrm{b}}$ & $19^{b}$ \\
\hline 4 & 0.2 & $20^{\mathrm{a}}$ & $20^{\mathrm{a}}$ & $20^{\mathrm{a}}$ & $30^{\mathrm{b}}$ & $30^{\mathrm{b}}$ \\
\hline 5 & 0.3 & $13^{a}$ & $13^{a}$ & $13^{\mathrm{a}}$ & $10^{\mathrm{b}}$ & $10^{\mathrm{b}}$ \\
\hline 6 & 0.3 & $16^{\mathrm{a}}$ & $16^{\mathrm{a}}$ & $16^{\mathrm{a}}$ & $24^{b}$ & $24^{\mathrm{b}}$ \\
\hline 7 & 0.4 & $20^{\mathrm{a}}$ & 19 & $20^{\mathrm{a}}$ & $15^{b}$ & $15^{b}$ \\
\hline 8 & 0.4 & $15^{\mathrm{a}}$ & 12 & $15^{\mathrm{a}}$ & $17^{b}$ & $17^{b}$ \\
\hline 9 & 0.5 & $15^{\mathrm{a}}$ & 10 & $15^{\mathrm{a}}$ & $12^{b}$ & $12^{\mathrm{b}}$ \\
\hline 10 & 0.5 & $12^{\mathrm{a}}$ & 11 & $12^{\mathrm{a}}$ & $31^{b}$ & $31^{b}$ \\
\hline 11 & 0.6 & $10^{\mathrm{a}}$ & 19 & $10^{\mathrm{a}}$ & $27^{b}$ & $27^{b}$ \\
\hline 12 & 0.6 & $25^{\mathrm{a}}$ & 10 & $25^{\mathrm{a}}$ & $17^{b}$ & $17^{b}$ \\
\hline 13 & 0.7 & $21^{a}$ & 11 & $21^{\mathrm{a}}$ & $25^{b}$ & $25^{\mathrm{b}}$ \\
\hline 14 & 0.7 & $18^{\mathrm{a}}$ & 13 & $18^{\mathrm{a}}$ & $10^{\mathrm{b}}$ & $10^{\mathrm{b}}$ \\
\hline 15 & 0.8 & $14^{a}$ & 17 & $14^{\mathrm{a}}$ & $15^{b}$ & $15^{b}$ \\
\hline 16 & 0.8 & $35^{\mathrm{a}}$ & 11 & $35^{\mathrm{a}}$ & $18^{b}$ & $18^{\mathrm{b}}$ \\
\hline 17 & 0.9 & 16 & 13 & 14 & 31 & \\
\hline 18 & 0.9 & 32 & 13 & 34 & 12 & \\
\hline 19 & 1.0 & $19^{a}$ & $19^{a}$ & $19^{\mathrm{a}}$ & $19^{a}$ & \\
\hline 20 & 1.0 & $39^{a}$ & $39^{a}$ & & $39^{a}$ & \\
\hline 21 & 0.9 & $17^{\mathrm{a}}$ & $17^{\mathrm{a}}$ & $17^{a}$ & $17^{\mathrm{a}}$ & \\
\hline 22 & 0.9 & $35^{\mathrm{a}}$ & $35^{\mathrm{a}}$ & $35^{\mathrm{a}}$ & $35^{\mathrm{a}}$ & \\
\hline 23 & 0.8 & $27^{a}$ & $27^{a}$ & $27^{\mathrm{a}}$ & $27^{a}$ & \\
\hline 24 & 0.8 & & $20^{\mathrm{a}}$ & $20^{\mathrm{a}}$ & $20^{\mathrm{a}}$ & \\
\hline 25 & 0.7 & & $22^{\mathrm{a}}$ & $22^{\mathrm{a}}$ & $22^{\mathrm{a}}$ & \\
\hline 26 & 0.7 & & $33^{a}$ & $33^{\mathrm{a}}$ & $33^{a}$ & $33^{\mathrm{a}}$ \\
\hline 27 & 0.6 & & $37^{a}$ & $28^{\mathrm{a}}$ & $37^{a}$ & $37^{a}$ \\
\hline 28 & 0.6 & & $33^{a}$ & $33^{a}$ & & $33^{\mathrm{a}}$ \\
\hline 29 & 0.5 & & $21^{\mathrm{a}}$ & & & $21^{\mathrm{a}}$ \\
\hline 30 & 0.5 & & 28 & & & 35 \\
\hline 31 & 0.4 & & & & & 12 \\
\hline 32 & 0.4 & & & & & 12 \\
\hline
\end{tabular}

Note-The superscripts $a$ and $b$ indicate that a particular subject on the particular condition with the letter was not advanced to the next condition until that subject, as well as the other subjects with that letter on that condition, met the stability criteria. If there are no superscripts, that subject was advanced to the next condition when it reached stability. Rats 1,2, and 3 began the experiment with the larger, more delayed reinforcer assigned to the left lever, and Rats 4 and 5 with the larger, more delayed reinforcer assigned to the right lever. For subsequent conditions, either response effort or the side to which the larger, more delayed reinforcer was assigned was changed for each rat. More specifically, when the condition number increased from an odd number to an even number, the side to which the larger, more delayed reinforcer was assigned was changed, and when the condition was increased from an even to an odd number, response effort was changed

self-control responses or for the number of choice changes could be the highest or the lowest for that rat in that condition.

Some of the values listed in Table 1 have a letter following the value. The letter indicates that the particular subject with the letter was not advanced to the next condition until all of the other subjects with that letter also met stability criteria. The reason that this additional group criterion for changing conditions was not used throughout the experiment was that, as the force required to operate the levers increased, some subjects initially had difficulty responding and had to be exposed to the previous force requirement for several sessions.

It should be noted that, as the force required to operate the levers increased, 2 subjects made few or no effective responses for an entire condition (see Subjects 3 and 5). In these cases, the rats did not 
respond again until exposed to a lower response force condition. Additionally, at various points during the experiment, rats had to cease completely their participation in the experiment because of health problems. For these reasons, only for the first 16 conditions were all of the subjects exposed to the same conditions.

\section{RESULTS}

All analyses were conducted using the means of the last five (stable) sessions' free-choice data from each condition. All data reported are from conditions for which all of the trials were completed by that rat. There were no significant differences between the data collected when the larger, more delayed reinforcer was available for left leverpresses and the data collected when it was available for right leverpresses. Therefore, the data from each pair of conditions were combined for each response force level. Three dependent variables were examined separately for each pair of response force conditions and for each subject: initial proportion of self-control choices (the proportion of choices made for the larger, more delayed reinforcer before any choice changes had occurred), the number of choice changes per session, and the latency to make an initial choice.

Figure 2 shows the initial proportion of self-control choices for each subject for each pair of response force conditions, in the order in which the subjects experienced these conditions (ascending and then descending values of response force). This figure shows that, for each of the 5 subjects, the maximum value of the proportion of selfcontrol choices occurred as the force required to operate the levers increased, with these maxima occurring at forces between 0.5 and $0.9 \mathrm{~N}$. Then, after one or more conditions (depending on the subject), the proportion of self-control choices tended to decrease. The bottom right panel of Figure 2 shows the data combined for all of the subjects. A one-way analysis of variance (ANOVA), performed on the data for the ascending $0.1-0.8 \mathrm{~N}$ conditions, yielded an effect of response force $[F(7,28)=3.20, p<$ $.05]$. Only these conditions were used for the ANOVA, because these were the only conditions to which all of the subjects were exposed; comparisons involving other conditions would have involved comparing data from different sets of subjects. Figure 2 also reveals that, in 13 of the 15 cases, the rats' self-control proportions for the descending conditions tended to be lower than those for the corresponding ascending conditions.

Although the rats were allowed to change their choice from the larger, delayed reinforcer to the smaller, less delayed reinforcer, only Rat 5, in the last several descending conditions, and Rat 3 changed their initial choices more than occasionally. The mean number of choice changes for the other 3 rats for the last five sessions of each condition never exceeded 1.0 , and was often 0 . Given that the rats made few, if any, choice changes across conditions, the results for the final proportions of self-control choices (self-control choices after any choice changes had been made) were very similar to the results for initial self-control choices. Therefore, data for the final proportions of self-control choices are not reported.

Figure 3 is similar to Figure 2, except that the dependent variable is mean initial free-choice response latency. This figure shows that, similar to Figure 2, for 4 of the 5 subjects, the free-choice response latency increased as response force increased. Unfortunately, 3 of these 4 subjects did not consistently respond on many of the descending conditions, so it is difficult to determine the effect of the descending conditions on latency. The bottom right panel of Figure 3 shows the data combined for all of the subjects. A one-way ANOVA performed on the data for the ascending $0.1-0.8 \mathrm{~N}$ conditions (the conditions to which all of the subjects were exposed) yielded an effect of response force $[F(7,28)=6.63, p<.001]$. Figure 3 also reveals that, in 12 of the 15 cases, the rats' choice latency for the descending conditions was lower than that for the corresponding ascending conditions.

Given that both choice latency and the initial proportion of self-control responses increased as the effort required to make a choice increased, the relationship between choice latency and the initial self-control choices was further explored. This relationship is plotted in Figure 4 for each subject and for all subjects combined. Correlations for each of the individual subjects between response latency and the initial proportion of self-control choices are significant for every subject except Rat 5 $(r=.60, p=.05 ; r=.57, p<.05 ; r=.72, p<.01 ; r=$ $.59, p<.05 ; r=.35, p=.29$, for Rats $1-5$, respectively). The correlation between response latency and the initial proportion of self-control choices was also significant for all of the subjects combined $(r=.35, p<.01)$.

\section{DISCUSSION}

The results indicate that, in general, self-control increases as response effort increases within a certain range of force, up to about $0.8 \mathrm{~N}$. Beyond that range, some of the rats in the present experiment ceased responding. The resulting small number of subjects in subsequent conditions makes it difficult to draw any conclusions about the behavior of the rats subsequent to the ascending $0.8-\mathrm{N}$ condition. However, the rats' proportions of initial self-control choices tended to be lower for the descending than for the same ascending conditions.

Interpretation of the asymmetrical results from the ascending and descending conditions is somewhat problematic because, in the present experiment, response force and experience were confounded. In order to ensure responding, all of the subjects were exposed to the ascending conditions prior to the descending conditions. The results from the descending conditions suggest that extensive experience with high effort to obtain reinforcers in a self-control paradigm meliorates or removes the increase in self-control caused by increased response force. This suggestion seems inconsistent with the results from previous research in which experience with response ef- 

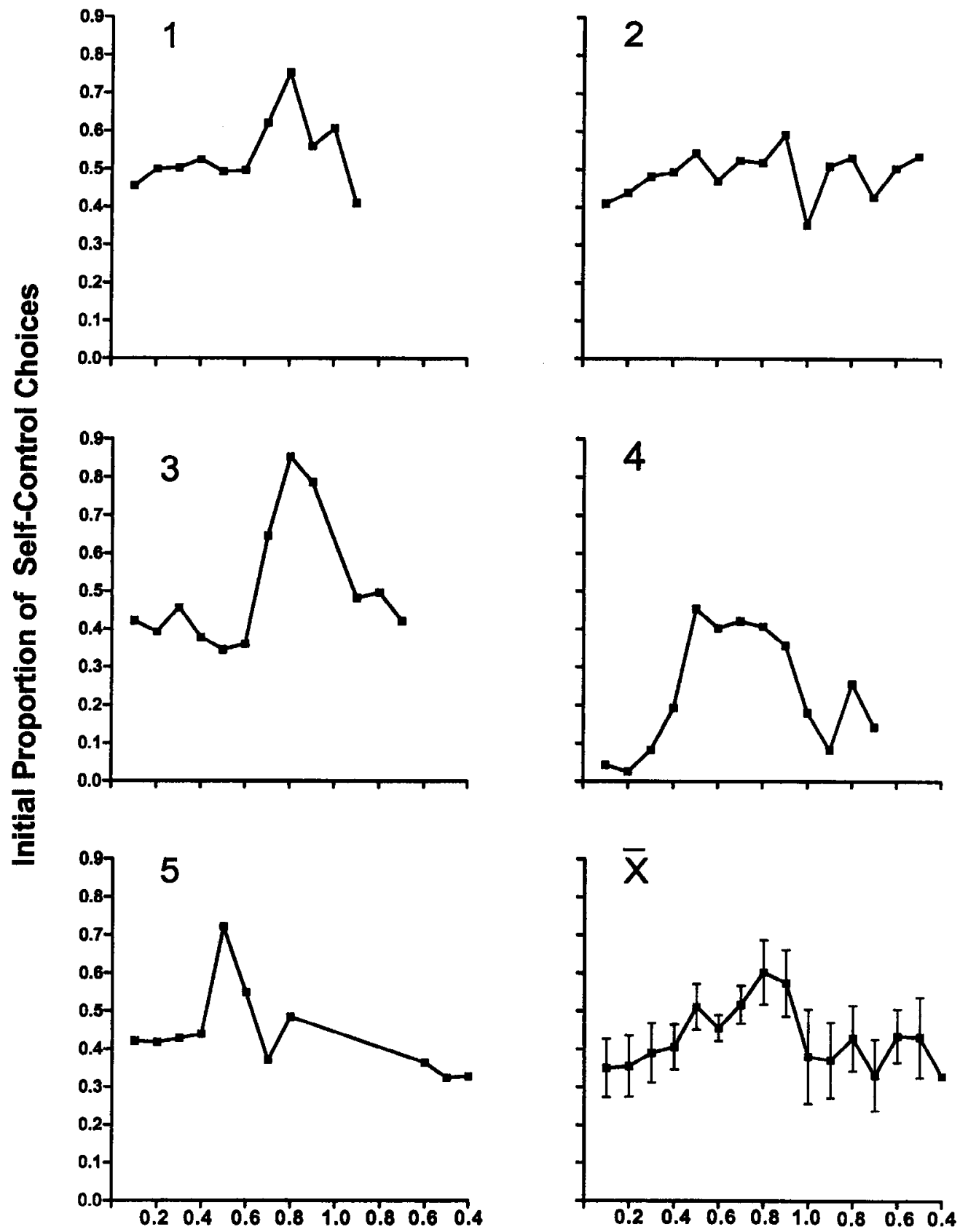

Force Condition (N)

Figure 2. Initial proportion of self-control choices for each subject for each pair of response force conditions. Means and standard errors across subjects are also shown in the bottom right panel.

fort increased self-control (Eisenberger \& Adornetto, 1986; Eisenberger et al., 1985; Eisenberger et al., 1989). However, in that prior research, different experimental paradigms were used to expose the subjects to high-effort responding and to assess self-control, which was not the case in the present research. In addition, the prior proce- dures compared choices for alternatives that differed in effort and not necessarily delay, another difference from the present procedure. The apparent inability of the present study to replicate the degree of self-control in the descending conditions is consistent with previous research that has found that, as rats gain experience with a spe- 

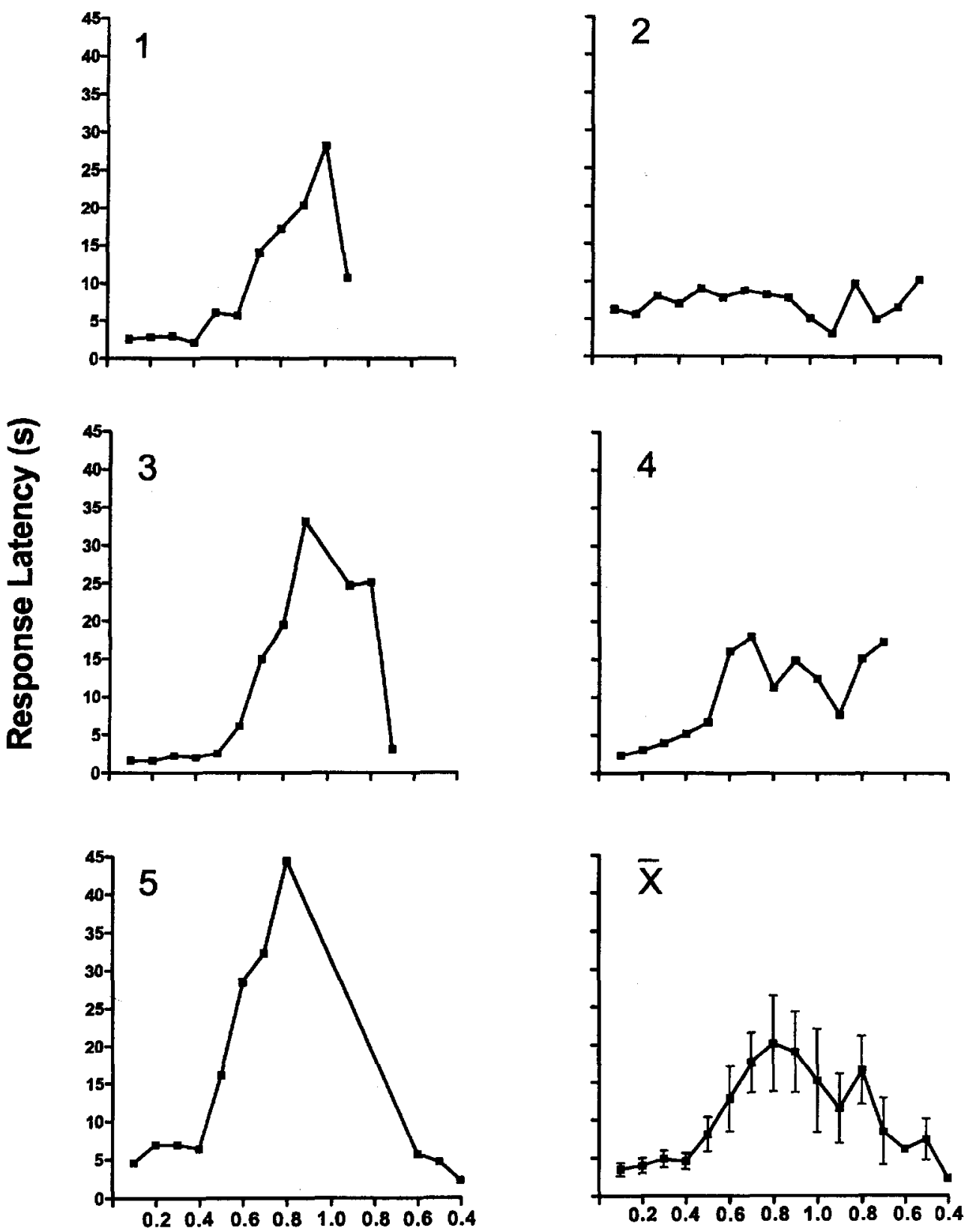

Force Condition (N)

Figure 3. Initial free-choice response latency for each subject for each pair of response force conditions. Means and standard errors across subjects are also shown in the bottom right panel.

cific required response, the amount of energy that they expend to make that response decreases (Brener \& Mitchell, 1989). This finding suggests that, for the descending force conditions in the present experiment, the rats may have been exposed to functionally lower required response forces than was the case for the comparable ascending conditions.
One explanation for the initial increase in self-control observed for the ascending conditions is that the rats responded so as to increase the duration of their access to food, which, in the present procedure, could only be accomplished by their making self-control responses. This effect would be similar to the fact that animals increase the duration of a meal or take larger prey when the amount 
1

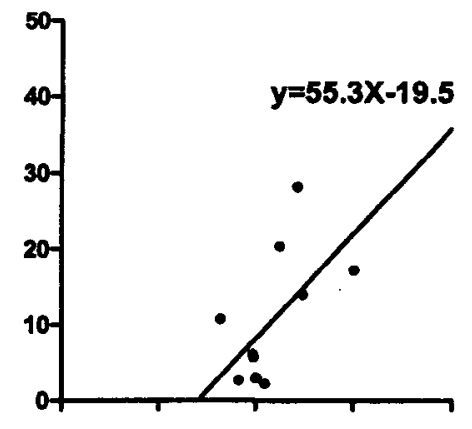

3

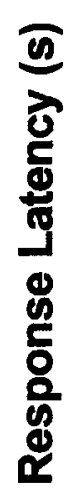

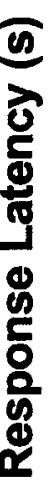
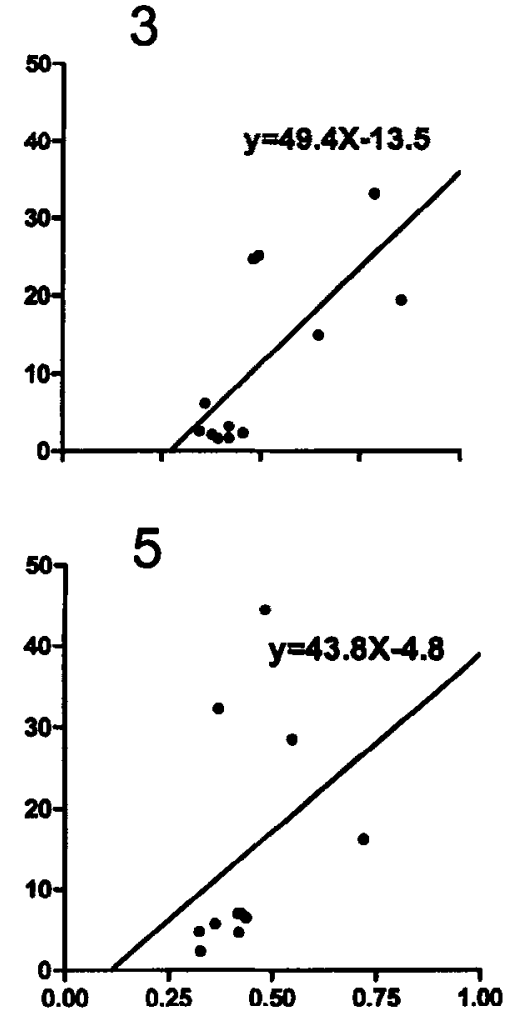

2

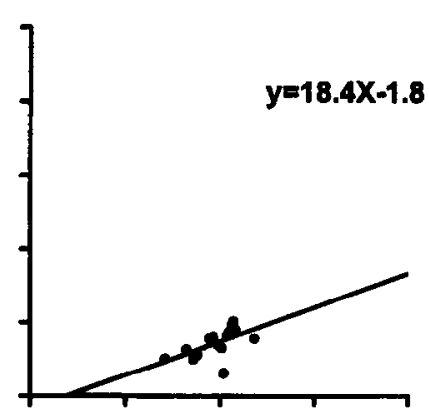

4

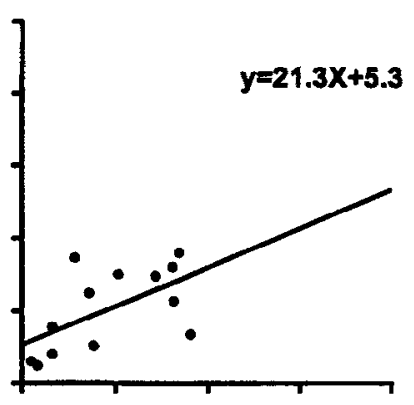

Combined

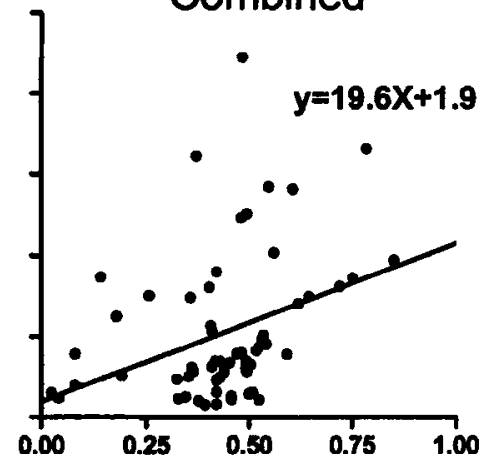

Initial Proportion of Self-Control

Figure 4. Free-choice response latency as a function of proportion of self-control choices, shown separately for each subject and for all subjects combined. The best fitting lines, calculated by the method of least squares, are also shown.

of effort required to obtain the meal or prey is increased (Collier, 1982; Collier \& Rovee-Collier, 1980; Stephens \& Krebs, 1986).

The present results can also be explained by the models of self-control mentioned in the introduction (the generalized matching law, incentive theory, and the hyperbolic decay model), if the cost of obtaining the alternatives and, hence, the net amount of energy gained from each alternative are taken into account. When cost and energy are considered in this way, the results of the present ex- periment are consistent with the predictions made by these models.

The rats in the present experiment made few choice changes during the delay to the larger reinforcer, unlike pigeons responding on a similar procedure (Logue \& Peña-Correal, 1984). These results occurred despite the similarity in the number of initial self-control responses made by the pigeons and the rats. Differences in the response topographies of pigeons and rats, as well as differences in the procedures used with these two species, might 
have resulted in the differences in the results of the two experiments.

The latency to make a choice also increased as the effort required to make a response increased. These results are consistent with the findings of Alling and Poling (1995), who found that increased response effort decreases response rates and increases postreinforcement pauses. For 4 out of 5 of the rats, the relationship between self-control and response latency was statistically significant, as were the combined data for all of the rats. It is, therefore, possible that increases in response latency, instead of increases in response force, might have caused the increases in self-control. However, note that for none of the rats was the mean latency long enough to affect the rate of reinforcement from either the self-control or the impulsive alternative; for both alternatives, reinforcers were delivered at the rate of one per minute. Further, although there is much research indicating that the delay to reinforcement directly following a response can affect choice (see Logue, 1988, for a review), there is no research indicating that nonhuman subjects' choices in a discretetrial procedure are affected by the time between presentation of the choice alternatives and the subsequent choice response.

Whether or not the effect is mediated by response latency, this experiment has demonstrated that, as long as responding is maintained, rats' self-control can be increased by increasing required response effort. These results, combined with prior research, suggest that any manipulation that can increase the cost of making a choice should be effective at decreasing impulsiveness. However, if the cost of making a response becomes too great, responding may cease, as occurred in the present experiment. The present experiment adds to a growing body of literature that has demonstrated a variety of effective methods for increasing self-control.

\section{REFERENCES}

Ainslie, G. W. (1974). Impulse control in pigeons. Journal of the Experimental Analysis of Behavior, 21, 485-489.

Alling, K., \& Poling, A. (1995). The effects of differing responseforce requirements on fixed-ratio responding of rats. Journal of the Experimental Analysis of Behavior, 63, 331-346.

BAUM, W. M. (1974). On two types of deviation from the matching law: Bias and undermatching. Journal of the Experimental Analysis of Behavior, 22, 231-242.

Brener, J., \& Mitchell, S. (1989). Changes in energy expenditure and work during response acquisition in rats. Journal of Experimental Psychology: Animal Behavior Processes, 15, 166-175.

COLlieR, G. H. (1982). Determinants of choice. In D. J. Bernstein (Ed.), Nebraska symposium on motivation, 1981 (pp. 69-127). Lincoln: University of Nebraska Press.

Collier, G. H., \& Rovee-Collier, C. K. (1980). A comparative analysis of optimal foraging behavior: Laboratory simulations. In A. C. Kamil \& T. Sargent (Eds.), Foraging behavior: Ecological, etholog- ical, and psychological approaches (pp. 39-76). New York: Garland STPM Press.

EISENBERGER, R., \& ADORNETTO, M. (1986). Generalized self-control of delay and effort. Journal of Personality \& Social Psychology, 51, 1020-1031.

Eisenberger, R., Masterson, F. A., \& Lowman, K. (1982). Effects of previous delay of reward, generalized effort, and deprivation on impulsiveness. Learning \& Motivation, 13, 378-389.

Eisenberger, R., Mitchell, M., \& Masterson, F. A. (1985). Effort training increases generalized self-control. Journal of Personality \& Social Psychology, 49, 1294-1301.

Eisenberger, R., Weier, F., Masterson, F. A., \& Theis, L. Y. (1989). Fixed-ratio schedules increase generalized self-control: Preference for large rewards despite high effort or punishment. Journal of Experimental Psychology: Animal Behavior Processes, 15, 383-392.

FANTINO, E., \& DAVISON, M. (1983). Choice: Some quantitative relations. Journal of the Experimental Analysis of Behavior, 40, 1-13.

GRosCh, J., \& NeURINGER, A. (1981). Self-control in pigeons under the Mischel paradigm. Journal of the Experimental Analysis of Behavior, 35, 3-21

KILLEEN, P. R. (1982). Incentive theory: II. Models for choice. Journal of the Experimental Analysis of Behavior, 38, 217-232.

LogUe, A. W. (1988). Research on self-control: An integrating framework. Behavioral \& Brain Sciences, 11, 665-709.

LoGUE, A. W. (1995). Self-control: Waiting until tomorrow for what you want today. Englewood Cliffs, NJ: Prentice-Hall.

Logue, A. W., \& MAZUR, J. E. (1981). Maintenance of self-control acquired through a fading procedure: Follow-up on Mazur and Logue (1978). Behaviour Analysis Letters, 1, 131-137.

Logue, A. W., \& Peña-Correal, T. E. (1984). Responding during reinforcement delay in a self-control paradigm. Journal of the Experimental Analysis of Behavior, 41, 267-277.

Logue, A. W., Rodriguez, M. L., Peña-Correal, T. E., \& Mauro, B. C. (1984). Choice in a self-control paradigm: Quantification of experience-based differences. Journal of the Experimental Analysis of Behavior, 41, 53-67.

Logue, A. W., Smith, M. E., \& Rachlin, H. (1985). Sensitivity of pigeons to prereinforcer and postreinforcer delay. Animal Learning \& Behavior, 13, 181-186.

MAzur, J. E. (1984). Tests of an equivalence rule for fixed and variable reinforcer delays. Journal of Experimental Psychology: Animal Behavior Processes, 10, 426-436.

Mazur, J. E., \& Logue, A. W. (1978). Choice in a "self-control" paradigm: Effects of a fading procedure. Journal of the Experimental Analysis of Behavior, 30, 11-17.

NeITZ, J., \& JACOBS, G. H. (1986). Reexamination of spectral mechanisms in the rat (Rattus norvegicus). Journal of Comparative Psychology, 100, 21-29.

RaChlin, H., \& GREen, L. (1972). Commitment, choice and selfcontrol. Journal of the Experimental Analysis of Behavior, 17, 15-22.

Stephens, D. W., \& Krebs, J. R. (1986). Foraging theory. Princeton, NJ: Princeton University Press.

Tobin, H., Chelonis, J. J., \& Logue, A. W. (1993). Choice in a selfcontrol paradigm using rats. Psychological Record, 43, 441-454.

Tobin, H., \& Logue, A. W. (1994). Self-control across species ( $\mathrm{Co}-$ lumba livia, Homo sapiens, and Rattus norvegicus). Journal of Comparative Psychology, 108, 126-133.

Tobin, H., Logue, A. W., Chelonis, J. J., Ackerman, K. T., \& MaY, J. G., III (1996). Self-control in the monkey Macaca fascicularis. Animal Learning \& Behavior, 24, 168-174.

(Manuscript received November 17, 1997; revision accepted for publication January 12, 1998.) 